\title{
Estratégia para erradicação de focos da Doença de Aujeszky em suínos no Estado de São Paulo ${ }^{1}$
}

\author{
Luís Guilherme de Oliveira ${ }^{2 *}$, Maria E.F. Oliveira ${ }^{3}$, Bruna Alexandrino ${ }^{3}$ e Samir I. Samara ${ }^{3}$
}

\begin{abstract}
Oliveira L.G., Oliveira M.E.F., Alexandrino B. \& Samara S.I. 2012. [Strategy for eradication of outbreaks of Aujeszky's Disease in pigs in the São Paulo state.] Estratégia para erradicação de focos da Doença de Aujeszky em suínos no Estado de São Paulo. Pesquisa Veterinária Brasileira 32(11):1121-1126. Departamento de Medicina Veterinária Preventiva e Reprodução Animal, Faculdade de Ciências Agrárias e Veterinárias, Universidade Estadual Paulista, Via de acesso Prof. Paulo Donato Castellane s/n, Jaboticabal, SP14884-900, Brazil. E-mail: luis.guilherme@cda.sp.gov.br

This study aimed to evaluate strategies for eradication of Aujeszky Disease (AD) virus infection after outbreaks in swine production systems in Sao Paulo state. Two outbreaks were identified in Cerqueira César county. The first outbreak coursed with seropositive pigs (outbreak 1), and the other with pigs presenting clinical signs (outbreak 2). In order to eradicate the infection, two sanitary strategies were tested: (1) eradication of animals with positive serology and (2) by gradual depopulation, with a follow up of 12 months. The serology eradication was used in outbreak 1 , and included the identification, isolation and slaughter of positive animals; followed by vaccination of negative animals and replacement with pigs from farms free of the disease. At the beginning, $68 \%$ of pigs were positive, and at the end it declined to $51 \%$. In outbreak 2 , gradual depopulation was used, and all animals were sent to sanitary slaughter, until facilities were completely empty. Afterwards, animals free of the disease were used for repopulation. It was seen that the last strategy was more effective because eradicated the infection.
\end{abstract}

INDEX TERMS: Aujeszky's disease, swine, eradication, animal health protection, São Paulo state.

RESUMO.- Este trabalho teve como objetivo a avaliação de duas estratégias para erradicação de focos da doença de Aujeszky (DA) em suínos criados comercialmente no estado de São Paulo. Foram identificados dois focos da enfermidade, no município de Cerqueira César, um apresentando somente animais sororreagentes (Foco 1) e outro, casos clínicos da doença (Foco 2). Foram avaliadas duas estratégias de erradicação, uma por eliminação dos sororreagentes e outra por despovoamento gradual, com acompanhamento durante 12 meses. A erradicação por eliminação dos sororreagentes foi aplicada no Foco 1 e compreendeu na identi-

\footnotetext{
${ }^{1}$ Recebido em 7 de dezembro de 2011.

Aceito para publicação em 8 de agosto de 2012.

${ }^{2}$ Coordenadoria de Defesa Agropecuária (CDA), Secretaria de Agricultura e Abastecimento do Estado de São Paulo, EDA de Jaboticabal, Rua Barão do Rio Branco 372, Jaboticabal. SP 14870-330, Brasil. *Autor para correspondência: luis.guilherme@cda.sp.gov.br

${ }^{3}$ Departamento de Medicina Veterinária Preventiva e Reprodução Animal, Faculdade de Ciências Agrárias e Veterinárias (FCAV), Universidade Estadual Paulista (Unesp), Via de Acesso Prof. Paulo Donato Castellane s/n, Jaboticabal, SP 14884-900, Brasil.
}

ficação por exame sorológico, isolamento e abate dos positivos; vacinação dos negativos e reposição no plantel com animais provenientes de propriedade livre. No início dos trabalhos, $68 \%$ do plantel era positivo e ao final $51 \%$. No Foco 2 utilizou-se o despovoamento gradual, onde todos os animais foram enviados ao abate sanitário, realizado vazio sanitário nas instalações, seguido pelo repovoamento com animais livres. Esta última estratégia, nas condições desse trabalho, mostrou-se a mais eficaz, pois erradicou a DA.

TERMOS DE INDEXAÇÃO: Doença de Aujeszky, suínos, erradicação, defesa sanitária animal, São Paulo.

\section{INTRODUÇÃO}

A Doença de Aujeszky (DA) está entre as doenças de maior impacto econômico na suinocultura. Esta enfermidade viral que apresenta distribuição mundial é responsável por grandes perdas, não só aquelas causadas pela doença, como também pelos gastos destinados ao seu controle e embargos na comercialização (Zanella et al. 2007, Lowell et al. 2008). 
No Brasil a DA é relatada desde 1912 (Carini \& Maciel 1912) e já foi detectada em várias regiões brasileiras (Filippsenet al. 2001, Souza et al. 2002, Schaefer et al. 2006). Para a Organização Mundial de Saúde Animal (OIE), a DA é considerada doença de caráter notificável (OIE 2009) e no nosso país existem normativas específicas do Ministério da Agricultura, Pecuária e Abastecimento (MAPA) que regulamentam o controle da DA (Brasil 2007). A DA já foi ou está erradicada em vários países (Zanella et al. 2007).

Os estados brasileiros, pelos seus serviços oficiais veterinários juntamente com a demanda do setor produtivo, têm desenvolvido ações de combate e erradicação da DA, como é o exemplo de Santa Catarina e Rio Grande do Sul (Mores \& Zanella 2003, Groff et al. 2005, Mores et al. 2005, Miele et al. 2008). Pesquisas demonstram que no estado de São Paulo há circulação do vírus responsável pela DA (Secretaria de Agricultura e Abastecimento 1986, Cunha et al. 2006, Villalobos et al. 2008).

A suinocultura é uma atividade econômica de expressiva participação no agronegócio paulista, sendo que o estado de São Paulo é o quinto maior rebanho suíno do Brasil e o estado da federação que mais consome carne suína (Torres et al. 2009, ABIPECS 2010). Programas de erradicação estão em curso em vários países e regiões e, é prioridade para as autoridades veterinárias que desenvolvem trabalhos em prol a suinocultura. Um programa de erradicação traz benefícios não só para o conjunto da cadeia produtiva da carne suína, mas também são beneficiários principalmente os suinocultores, empresas e cooperativas agroindustriais (Mores et al. 2005, Miele et al. 2008).

0 objetivo desse trabalho foi avaliar duas estratégias de ação adotadas para erradicação da DA eliminando os focos nos sistemas de produção de suínos selecionados. As estratégias de erradicação aplicadas foram: a vacinação e eliminação dos sororreagentes (A) e o despovoamento gradual (B).

\section{MATERIAL E MÉTODOS}

A identificação dos estabelecimentos de criação infectados pela DA foi realizada com base nas informações cedidas pela Coordenadoria de Defesa Agropecuária, órgão executor das atividades de defesa sanitária animal no Estado de São Paulo. 0 critério utilizado para seleção das unidades experimentais (granja) foi o histórico de uso da vacina contra o vírus da DA e a ocorrência de focos da doença. Foram selecionadas duas granjas que se localizavam no município de Cerqueira César, região de maior densidade de suínos do estado de São Paulo (Torres et al. 2009).

Procederam-se às medidas de atendimento inicial a focos, conforme prevê o plano de contingência para DA (Brasil 2007). 0 critério de escolha da estratégia a ser aplicada foi a partir da gravidade da doença, ou seja, mortalidade devido a DA:

- Presença de animais sororeagentes para DA e histórico do uso de vacina: aplicação da "Estratégia A - erradicação por eliminação dos sororreagentes";

- Presença de sinais clínicos de doença de Aujeszky, aumento da mortalidade e isolamento viral: aplicação da "Estratégia B - erradicação por despovoamento gradual".

Estratégia A, erradicação por eliminação dos sororreagentes

Esta metodologia compreendeu na identificação, isolamento e abate sanitário dos positivos, vacinação dos negativos, reposição com reprodutores livres de DA, inspeções regulares e avaliação dos índices produtivos do plantel. A aplicação desta estratégia teve a duração de 12 meses, com início em maio de 2008 e término em abril de 2009 .

Para a identificação dos animais infectados procedeu-se colheita de sangue de todos os reprodutores existentes na granja, e processados no laboratório de raiva e encefalites do Instituto Biológico em São Paulo, SP, onde foi realizado o teste de ELISA.

A partir dos resultados desta avaliação inicial de todos os reprodutores, os animais com resultados positivos e suspeitos para o teste de ELISA foram identificados para posteriormente serem enviados ao abate sanitário. Neste trabalho o animal com resultado suspeito foi tratado como positivo.

Os animais positivos foram separados e colocados em outra instalação, dentro do mesmo estabelecimento de criação, sem contato com os demais reprodutores. Este local foi isolado e adaptado a normas específicas de biosseguridade com manejo diferenciado, realizado por funcionário exclusivo, equipamentos de alimentação, limpeza e manejo próprios, além de ser feito a desinfecção das instalações com mais frequência.

Realizou-se vacinação nos reprodutores negativos para evitar disseminação da doença clínica. A vacina utilizada era uma vacina inativada contra a $\mathrm{DA}^{4}$, esse vírus vacinal possui uma deleção na parte do genoma que corresponde a glicoproteína gE (gE-), possibilitando a distinção por sorologia dos animais vacinados dos infectados pelo vírus de campo.

A reposição do plantel de reprodutores foi feita com animais comprovadamente negativos para DA, sendo feitos no período de quarentena dois testes de ELISA para DA com intervalo de 60 dias.

\section{Estratégia B, erradicação por despovoamento gradual}

Nesta metodologia de erradicação da DA por despovoamento gradual, todo o rebanho foi eliminado (abate sanitário) dentro de um período máximo de noventa dias, a contar do diagnóstico inicial, no qual se seguiu os seguintes preceitos:

- Sacrifício sanitário imediato dos suínos com doença clínica;

- Vacinação dos leitões maiores de sete dias de idade, até ser completado o despovoamento do estabelecimento de criação, para evitar disseminação da doença clínica;

- Abate sanitário imediato de fêmeas não gestantes, fêmeas até sessenta dias de gestação e leitoas de reposição;

- Fêmeas em lactação e com mais de sessenta dias de gestação aguardavam o desmame dos leitões e depois eram enviadas a abate sanitário assim que atingisse condições para tal;

- Leitões em maternidade e creche eram vacinados e recriados em outro sítio de criação (unidades de produção segregadas e isoladas), assim que atingiram o peso aproximado de cem kg eram encaminhados a abate sanitário;

- Procedeu-se à higienização com protocolo de cinco etapas: limpeza seca, limpeza úmida, aplicação do limpador ou detergente, enxágüe e desinfecção. 0 estabelecimento de criação fez a um período de vazio sanitário de trinta dias após a retirada dos últimos animais do rebanho. Houve a introdução de suínos sentinelas após o término do período de vazio sanitário, sendo considerada sentinela, o primeiro lote de leitoas de reposição. A condição de livre de DA do estabelecimento foi comprovada por meio da obtenção de duas sorologias negativas consecutivas, em intervalos de dois meses, seguindo a amostragem aleatória dos animais (Brasil 2002). A primeira sorologia foi realizada logo após a parição do primeiro lote de reprodutoras introduzidas anteriormente como sentinelas.

Os soros foram testados pelo método de ELISA anti-gpI do

\footnotetext{
${ }^{4}$ Cepa Phylaxia (gE-), Porcilis ${ }^{\circledR}$ Aujeszky INAC, Intervet ScheringPlough Animal Health.
} 


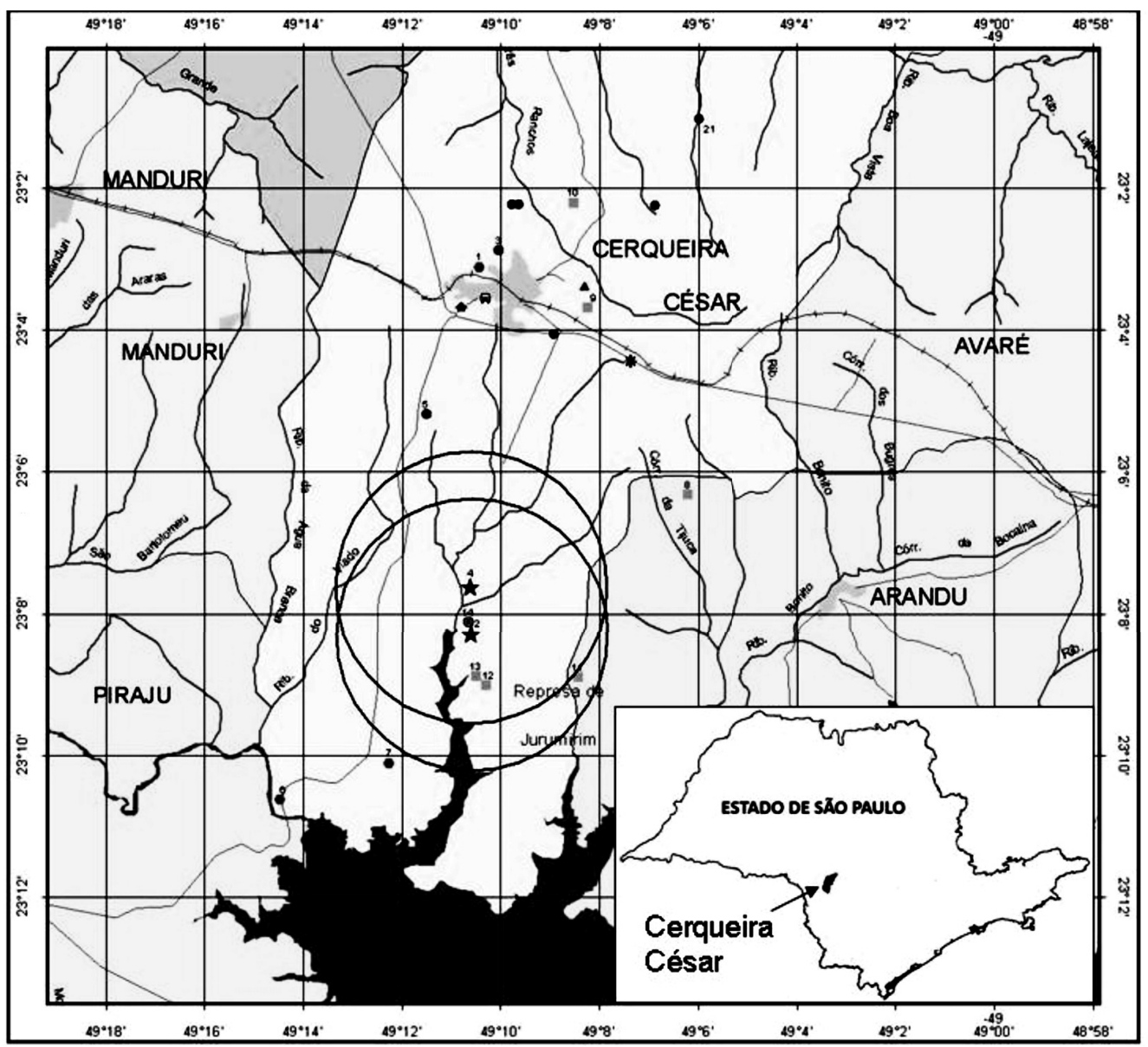

\section{Focos da Doença de Aujeszky

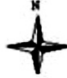

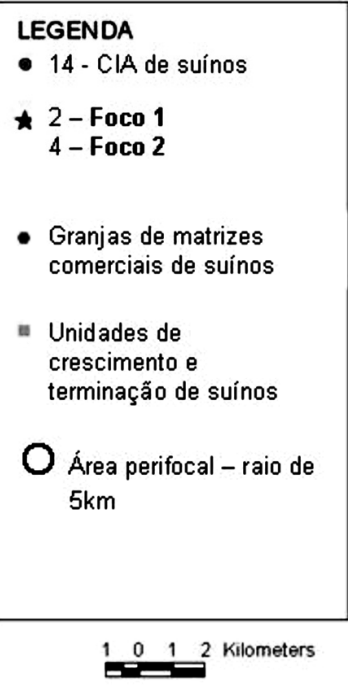

Fig.1. Mapa indicando, por meio de georreferenciamento, a localização do Foco 1 e Foco 2, estabelecimentos criadores de suínos na região e a determinação da zona perifocal.

vírus da DA que permite detectar anticorpos não induzidos por vacinas. 0 "kit" de ELISA utilizado foi o HerdChekAnti-PRVgpIAntibody Test Kits@, produzido pela IDEXX Laboratories, sendo a metodologia de análise feita conforme protocolo do fabricante.

\section{RESULTADOS}

Os dois estabelecimentos de criação identificados como focos para DA (Foco 1 e Foco 2) eram separados por uma distância menor que $5 \mathrm{~km}$, ou seja, estavam dentro da mesma zona perifocal (Fig.1). Tinham vínculo epidemiológico, pois pertenciam a um mesmo sistema integrado de produção. 0 Foco 1 praticava vacinação contra o vírus da DA e no Foco 2 havia aumento de mortalidade de leitões, sendo confirmada a infecção para a DA por meio do isolamento viral e da técnica de ELISA. Eram unidades de produção de leitões e no inicio do experimento o Foco 1 contava com 3.262 reprodutores alojados e o Foco 2 com 1.118 nas mesmas condições.

Estratégia A. O Foco 1 apresentou uma taxa de reposição da animais de 79,62\% durante o período de experimento, conforme mostra a Figura 2. Na Figura 3 está o comparativo entre os resultados iniciais (maio/2008) e finais (abril/2009) das avaliações sorológicas realizadas.

Estratégia B. Todo o procedimento de despovoamento foi realizado entre os meses de outubro de 2007 a fevereiro de 2008, o procedimento de higienização foi realizado no

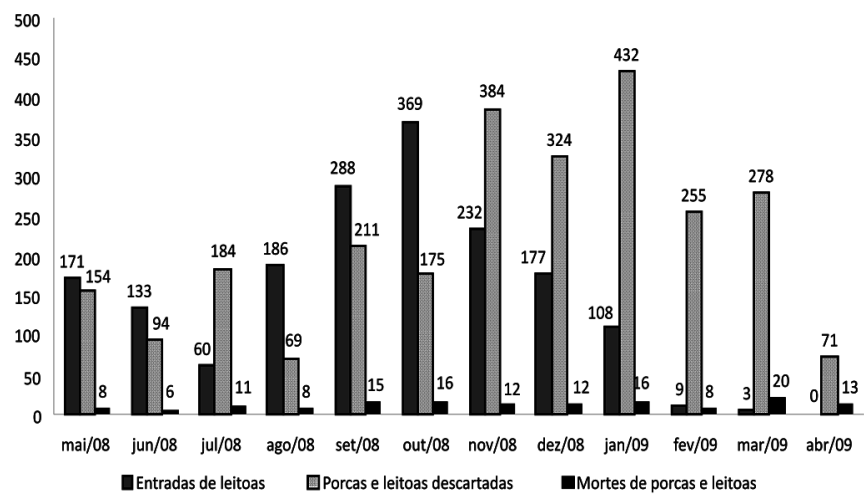

Fig.2. Eliminação dos animais infectados (porcas e leitoas descartadas), reposição do plantel (entrada de leitoas) e mortes de reprodutores (mortes de porcas e leitoas) na granja Foco $1 \mathrm{du}-$ rante 12 meses (maio de2008 a abril de 2009), o período de aplicação da estratégia 1 .

mês de fevereiro de 2008 e o vazio sanitário no mês subsequente. A Figura 4 mostra os totais de entrada e saída de reprodutores no sistema de criação avaliado durante a aplicação da estratégia $\mathrm{B}$, no período de 12 meses. Como esta última estratégia, nas condições desse trabalho, mostrou-se a mais eficaz, pois erradicou a DA do Foco 2, então também foi aplicada no final da fase experimental no Foco 1, que foi erradicado em janeiro de 2010. 


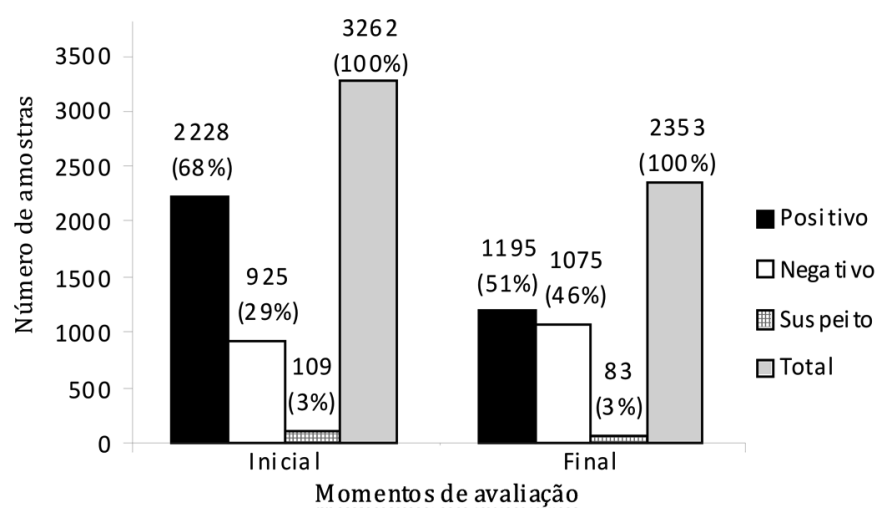

Fig.3. Total de amostras analisadas do Foco 1 pelo teste de ELISA, com seus respectivos resultados de positivo, negativo, suspeito e total, por momento de avaliação - inicial (maio de 2008) e final (abril de 2009) - na aplicação da estratégia 1.

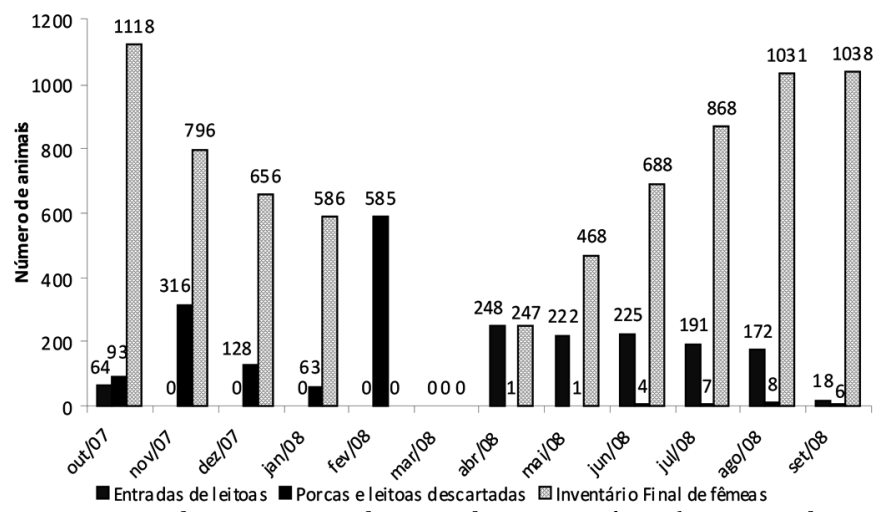

Fig.4. Reprodutores enviados ao abate sanitário (porcas e leitoas descartadas), mortes de reprodutores na granja (morte de porcas e leitoas), reposição do plantel (entradas de leitoas) e inventário final de fêmeas na granja Foco 2, avaliados durante 12 meses (outubro de 2007 a setembro de 2008), o período de aplicação da estratégia 2.

\section{DISCUSSÃO}

Os resultados obtidos neste trabalho foram alcançados por meio da eliminação dos focos de DA, porem no caso apresentado, demonstraram-se diferenças na eficiência dos métodos aplicados. 0 método de erradicação por eliminação dos sororreagentes, nas condições deste experimento, não foi eficiente. Segundo Mores et al. (2005), no Estado de Santa Catarina, o programa de erradicação da DA investigou 985 rebanhos, sendo que apenas $80(8,12 \%)$ conseguiram erradicar por sorologia, contra $238(24,16 \%)$ por despovoamento gradual, sendo este resultado um indicativo da eficiência do despovoamento.

Considerando que em SC (Mores et al. 2005) o número médio de reprodutores por rebanhos nas granjas onde foi aplicada erradicação por sorologia era de 216 e no experimento (Foco 1) havia 3.262 no início do estudo, possivelmente a diferença do tamanho do rebanho foi um fator determinante para o insucesso da erradicação por sorologia neste estudo.

Alguns países conseguiram erradicar a DA de seus plantéis usando a vacinação do rebanho e a eliminação dos sororreagentes (Rodrigues et al. 1990, Willemberg et al. 1996). Contudo, tem-se aplicado essa estratégia em reba- nhos onde a prevalência inicial é baixa, ou seja, menor que $10 \%$ (Mores et al. 2005), o que não foi o caso do Foco 1, onde a prevalência inicial foi de $68 \%$. Apesar da recomendação oficial (Brasil, 2007) ser despovoamento nos casos de alta prevalência, havia a necessidade de testar a erradicação por sorologia, pois esta é uma metodologia menor de impacto para o produtor.

0 fato de segregar animais na mesma propriedade, mesmo que em distintas instalações, também aumenta o risco de disseminação do vírus devido à pressão de infecção. A aplicação da higienização e vazio sanitário por galpão e, não em todas as instalações ao mesmo tempo, poderia ter facilitado a permanência do vírus e, consequentemente, proporcionado à infecção de outros animais. Soma-se o fato do vírus da DA ser um herpesvirus e como tal, estabelece latência (Kluge et al. 1999, Posadas \& Martinez 2005), assim dificultando o controle mesmo com programa de higienização e/ou uso de vacina. Comparando o resultado do método de erradicação por eliminação dos sororreagentes com o despovoamento gradual, o diferencial mais importante foi que o segundo possibilita o vazio sanitário em todas as instalações da propriedade ao mesmo tempo.

Tanto na Europa quanto no Brasil, os estabelecimentos que fizeram o despovoamento, vazio sanitário e repovoamento com animais livres não apresentaram uma re-infecção (Groff et al. 2005, Mores et al. 2005, Allepuzet al. 2009). Entretanto, foi relatada a ocorrência de DA em SC onde o repovoamento foi feito com animais que não possuíam garantias de livres da DA, então houve novamente a infecção pelo vírus da DA (Ciacci-Zanella et al. 2008).

Concomitantemente, deve-se considerar também que o período de 12 meses aplicado na eliminação dos animais infectados do Foco 1 aumentou a possibilidade da exposição ao vírus. 0 vírus encontrava-se na forma latente e a reativação poderia ter sido facilitada por diversos fatores do manejo, como estresse, aplicação de medicamentos imunossupressores, mudanças bruscas de temperatura, outras infecções, transporte, dentre outros (Aleman et al. 2001, Posadas \& Martinez 2005, Marcaccini et al. 2008).

Em outros países que usam métodos de erradicação por despovoamento, o resultado tem sido relatado como eficiente, porém nesses casos um fundo de indenização para os produtores faz parte do programa (Rodrigues et al. 1990, Muller et al. 2003, Lowell et al. 2008,). 0 mesmo foi feito no Brasil, no estado de Santa Catarina, que indenizou todos os criadores que participaram do programa de erradicação (Mores et al. 2005, Miele et al. 2008). No experimento aqui apresentado não houve indenizações. Excluindo-se os animais do Foco 2 que apresentaram sinais clínicos da enfermidade e foram sacrificados, todos os outros foram enviados ao abate sanitário e o proprietário recebeu pela carcaça, quando não houve condenações.

Normalmente a DA não determina lesões típicas que comprometem a qualidade higiênico-sanitária da carcaça (Kluge et al. 1999, Zanella et al. 2007, Avante et al. 2009), não sendo comum o registrado de condenações em frigoríficos. 0 abate sanitário dos animais sororreagentes amortizou o prejuízo da ocorrência do foco para o criador. 0 abate dos sororreagentes foi num período prolongado porque a 
demanda de carne de porcas estava instável na época e o produtor encontrava dificuldade para a venda.

A reorganização do sistema de produção foi determinante para a implementação da rastreabilidade e a aplicação de conceitos de biosseguridade. Com a implantação de uma unidade quarentenária foi possível fazer procedimentos de seleção de reprodutoras, vacinação e principalmente colheita de amostras para teste de ELISA para a comprovação da ausência da infecção pelo vírus da DA, e assim evitar o risco de disseminação pelas leitoas de reposição (Ciacci-Zanella et al. 2008). Para Mores et al. (2007), a disseminação do vírus da DA envolvendo comércio de reprodutores suínos de reposição é o grande responsável pela infecção de rebanhos. A legislação do MAPA (Brasil, 2002) reforça esse aspecto, pois determina que todas as granjas que comercializam reprodutores deverão estar livres.

A aplicação da estratégia B no Foco 1 foi realizada pois era necessário alcançar o objetivo de erradicação. 0 experimento foi desenvolvido sob influencia de múltiplos fatores inerentes a aspectos regionais e próprios das criações, entretanto, seus resultados podem servir de base para programas de erradicação em outras localidades. Vale ressaltar, ainda, que o maior desafio é a elaboração de normativas de erradicação da DA que possam ser aplicáveis a todas as realidades encontradas. Outro ponto importante a ser levado em consideração é que o presente estudo avaliou apenas uma propriedade para cada estratégia de erradicação utilizada.

\section{CONCLUSÃO}

Com base na metodologia aplicada e resultados alcançados, a estratégia de erradicação por eliminação dos sororreagentes não foi eficaz em rebanho populoso, com alta prevalência e sem vazio sanitário. Entretanto a estratégia de erradicação por despovoamento gradual foi eficiente no caso aqui relatado, possibilitando a erradicação da DA na respectiva granja.

Agradecimentos.- Os autores agradecem a equipe de médicos veterinários do Escritório de Defesa Agropecuária de Avaré/Coordenadoria de Defesa Agropecuária (CDA/SAA-SP) pela ajuda na execução do trabalho a campo e as pesquisadoras científicasdo Laboratório de Raiva e Encefalites Virais do Instituto Biológico de São Paulo pelo apoio na realização dos testes diagnósticos.

\section{REFERÊNCIAS}

ABIPECS 2010. Estatísticas. Associação Brasileira da Indústria Produtora e Exportadora de Carne Suína. Disponível em <http://www.abipecs.org. br/pt/estatisticas/mercado-interno.html> Acesso em 9 jul. 2010.

Aleman N., Quiroga M.I., Lopez Pena M.,Vazquez S., Guerrero F.H. \& Nieto J.M. 2001. Induction and inhibition of apoptosis by pseudorabies virus in the trigeminal ganglion during acute infection of swine. J. Virol. 75:469-479.

Allepuz A., Saez M., Solymosi N., Napp S. \& Casal J. 2009. The role of spatial factors in the success of an Aujeszky's disease eradication programme in a high pig density area (Northeast Spain, 2003-2007). Prev. Vet. Med. 91:153-160.

Avante M.L., Zangirolami Filho D., Ferreira M.G., Rosa B.T., Martins I.S. \& Avanzo M.F.B. 2009. Doença de Aujeszky. Revta Cient. Eletr. Med. Vet. $7(12)$.

Brasil 2002. Instrução Normativa no 19, de 15 de fevereiro de 2002, Minis- tério da Agricultura, Pecuária e Abastecimento. Diário Oficial da União, Poder Executivo, Brasília, DF, 1 mar. 2002, Seção 1, p.3.

Brasil 2007. Instrução Normativa no 08, de 3 de abril de 2007, Ministério da Agricultura, Pecuária e Abastecimento. Diário Oficial da União, Poder Executivo, Brasília, DF, 10 abr. 2007, Seção 1, p.1.

Carini A. \& Maciel J. 1912. La pseudorage ou paralysie bulbaire infectieuse, Bresil. Bulletin de La Societe de Pathologie Exotique et de Ses Filiales 5:576-578.

Ciacci-Zanella J.R., Amaral A.L., Ventura L.V., Mores N. \& Bortoluzzi H. 2008. Erradicação da doença de Aujeszky em Santa Catarina: importância da condição sanitária das leitoas de reposição. Ciência Rural 38 (3):749-754.

Cunha E.M.S., Nassar A.F.C., Lara M.C.C.S.H., Bersano J.G., Villalobos E.M.C. \& Oliveira J.C.F. 2006. Antibodies against pseudorabies virus in feral swine in southeast Brazil. Arq. Bras. Med. Vet. Zootec. 58(4):462-466.

Filippsen L.F., Leite D.M.G., Silva A. \& Vargas G.A. 2001. Prevalência de doenças infecciosas em rebanho de suínos criados ao ar livre na região sudoeste do Paraná, Brasil. Ciência Rural 31(2):299-302.

Groff F.H.S., Merlo M.A., Stoll P.A., Stepan A.L., Weiblen R. \& Flores E.F. 2005. Epidemiologia e controle dos focos da doença de Aujeszky no Rio Grande do Sul, em 2003. Pesq. Vet. Bras. 25:25-30.

Kluge J.P., Beran G.W., Hill H.T. \& Platt, K.B. 1999. Pseudorabies (Aujeszky's Disease), p.233-246. In: Straw B.E., D’allaire S., Mengeling W.L. \& Taylor D.J. (Eds), Diseases of Swine. $8^{\text {th }}$ ed. Iowa State University Press, Ames. $1181 \mathrm{p}$.

Lowell A.A., Black N., Hagerty T.J., Kluge J.P. \& Sundberg P. L. 2008. Pseudorabies (Aujesky's disease) and its eradication: A review of the U.S. experience. Tech. Bull. 1923, Animal and Plant Health Inspection Service, United States Department of Agriculture, Washington, DC. 244p.

Marcaccini A., Pena M.L., Quiroga M.I., Bermudez R., Nieto J.M. \& Aleman N. 2008. Pseudorabies virus infection in mink: A host-specificpathogenesis. Vet. Immunol. Immunopathol. 124:264-273.

Miele M., Girotto A.F., Mores M., Amaral A.L. \& Zanella J.R.C. 2008. Avaliação dos impactos econômicos, sociais e organizacionais do programa de erradicação da doença de Aujeszky no Estado de Santa Catarina. Comun. Téc. 472, Embrapa Suínos e Aves, Concórdia. 6p.

Mores N., Amaral A.L., Ventura L., Zanella J.R.C., Mori A., Dambros J.A., Provenzano G. \& Bisolo I. 2007. Disseminação do vírus da doença de Aujeszky, envolvendo o comércio de reprodutores suínos de reposição. Arq. Bras. Med. Vet. Zootec. 59(6):1382-1387.

Mores N., Amaral A.L., Ventura L., Zanella J.R.C. \& Silva V.S. 2005. Programa de erradicação da doença de Aujeszky no Estado de Santa Catarina. Circ. Téc. 44, Embrapa Suínos e Aves, Concórdia. 8p.

Mores N. \& Zanella J.R.C. 2003. Programa de erradicação da doença de Aujeszky no Estado de Santa Catarina. Documentos 81, Embrapa Suínos e Aves, Concórdia. 50p.

Muller T., Batza H.J., Schluter H., Conraths F.J. \& Mettenleiter T.C. 2003. Eradication of Aujeszky's disease in Germany. J. Vet. Med. 50(5):207-213.

OIE 2010. Terrestrial Animal Health Code. Capítulo 8.2. 2009, Organização Internacional de Epizootias. Disponível em <http://www.oie.int/eng/ normes/mcode/en_index.htm> Acesso 28 jun. 2010.

Posadas N.A. \& Martinez J.M.N. 2005. Infecção latente do vírus da doença de Aujeszky. Suis Brasil 2:10-19.

Rodrigues C.A., Gardner I.A. \& Carpenter T.E. 1990. Financial analysis of pseudorabies control and eradication in swine. J. Am. Vet. Med. Assoc. 197(10):1316-1323.

Schaefer R., Zanella J.R.C., Mores N., Pan K.A., Dambros R.M.F., Schiochet M.F. \& Coldebella M. 2006. Caracterization of Aujeszky's disease virus isolated from South Brazil in the last twenty years by restriction enzyme analysis. Braz. J. Microbiol. 37(3):390-394.

Secretaria de Agricultura e Abastecimento 1986. Diagnóstico da doença de Aujeszky no Estado de São Paulo. Doc. Téc. 66, Coordenadoria de Assistência Técnica Integral (CATI), São Paulo. 76p.

Souza C.M., Sobestiansky J., Matos M.P.C. \& Caiado K.L. 2002. Prevalência da infecção pelo vírus da doença de Aujeszky em matrizes de sistemas 
de produção que abastecem o mercado consumidor de Goiânia. Ciênc. Anim. Bras. 3(2):53-56.

Tamba M., Calabrese R., Finelli E. \& Cordioli P. 2002. Risk factors for Aujeszky's disease seropositivity of swine herds of a region of northern Italy. Prev. Vet. Med. 54:203-212.

Torres A.J., Pino F.A., Francisco V.L.F.S., Ângelo J.A., Maciel E.L.F., Drugowich M.I., Interliche P.H., Piedade J.A., Sousa A.C., Neto B.L. \& Caser D.V. 2009. Projeto LUPA 2007/08, Censo Agropecuário do Estado de São Paulo. IEA, CATI, SAA, São Paulo.

Vannier P., Vedeau F. \& Allemeersch C. 1997. Eradication and control programs against Aujeszky's disease (pseudorabies) in France. Vet. Microbiol. 55:167-173.
Villalobos E.M.C., Borges S.R.T., Figueiredo V.L.C., Lara M.C.C.S.H., Felicio P.S., Cunha M.S., Torelli C.S. \& Cunha E.M.S. 2008. Situação da doença de Aujeszky no Estado de São Paulo: Considerações preliminares para o reconhecimento de área livre. 21플 Reunião Anual do Instituto Biológico, São Paulo, SP, p.124. (Resumo)

Willemberg P., Leontides L., Ewald C., Mortensen S., Mclnerney J.P., Howe K.S. \& Kooij D. 1996. Effect of vaccination against Aujeszky's disease compared with test and slaughter program: epidemiological and economical evaluation. Acta Vet. Scand. 90(Suppl.):25-51.

Zanella C.J., Mores N. \& Sobestiansky J. 2007. Doença de Aujeszky, p.228238. In: Sobestiansky J. \& Barcellos D. (Eds), Doenças dos Suínos. Cânone Editorial, Goiânia. 768p. 